\title{
Fabrication of Magnetite/Silica/Titania Core-Shell Nanoparticles
}

\author{
Suh Cem Pang, Sze Yun Kho, and Suk Fun Chin \\ Department of Chemistry, Faculty of Resource Science and Technology, Universiti Malaysia Sarawak, Kota Samarahan, \\ 94300 Sarawak, Malaysia
}

Correspondence should be addressed to Suh Cem Pang, suhcem@gmail.com

Received 25 September 2012; Revised 26 November 2012; Accepted 27 November 2012

Academic Editor: Yanbao Zhao

Copyright (C) 2012 Suh Cem Pang et al. This is an open access article distributed under the Creative Commons Attribution License, which permits unrestricted use, distribution, and reproduction in any medium, provided the original work is properly cited.

$\mathrm{Fe}_{3} \mathrm{O}_{4} / \mathrm{SiO}_{2} / \mathrm{TiO}_{2}$ core-shell nanoparticles were synthesized via a sol-gel method with the aid of sonication. $\mathrm{Fe}_{3} \mathrm{O}_{4}$ nanoparticles were being encapsulated within discrete silica nanospheres, and a layer of $\mathrm{TiO}_{2}$ shell was then coated directly onto each silica nanosphere. As-synthesized $\mathrm{Fe}_{3} \mathrm{O}_{4} / \mathrm{SiO}_{2} / \mathrm{TiO}_{2}$ core-shell nanoparticles showed enhanced photocatalytic properties as evidenced by the enhanced photodegradation of methylene blue under UV light irradiation.

\section{Introduction}

Over the past decades, titanium dioxide $\left(\mathrm{TiO}_{2}\right)$ nanoparticles have gained much attention as a photocatalyst and catalyst support $[1,2] . \mathrm{TiO}_{2}$ nanoparticles have many advantages as compared to other photocatalysts, which include excellent high stability against chemical and photonic corrosion and high photocatalytic activity [3]. $\mathrm{TiO}_{2}$ nanoparticles of small mean particle sizes possess high surface area and photocatalytic activity. However, $\mathrm{TiO}_{2}$ nanoparticles of high surface area are thermally unstable and lose their surface area readily [3]. Therefore, much effort has been focused on coating of $\mathrm{TiO}_{2}$ on high surface area supports such as silica or alumina in order to stabilize $\mathrm{TiO}_{2}$ nanoparticles.

$\mathrm{TiO}_{2}$ nanoparticles could be difficult to recover and lost readily upon being dispersed into wastewater. One of the ways to overcome this problem is to coat $\mathrm{TiO}_{2}$ onto magnetite $\left(\mathrm{Fe}_{3} \mathrm{O}_{4}\right)$ cores and the resulting $\mathrm{Fe}_{3} \mathrm{O}_{4} / \mathrm{TiO}_{2}$ core-shell nanoparticles can be recovered easily through manipulation by external magnetic field. Li et al. synthesized $\mathrm{Fe}_{3} \mathrm{O}_{4} / \mathrm{TiO}_{2}$ nanocomposite photocatalyst using a sol-gel method [3]. However, it was difficult to achieve complete coating of $\mathrm{Fe}_{3} \mathrm{O}_{4}$ nanoparticles with $\mathrm{TiO}_{2}$ at nanometer scale using the sol-gel method. Besides, $\mathrm{TiO}_{2}$ would oxidize $\mathrm{Fe}_{3} \mathrm{O}_{4}$ nanoparticles and lead to a reduction of magnetic moment. Some researchers had attempted to coat a thin layer of $\mathrm{SiO}_{2}$ between $\mathrm{Fe}_{3} \mathrm{O}_{4}$ nanoparticles and $\mathrm{TiO}_{2}$ shell. The presence of a $\mathrm{SiO}_{2}$ layer between $\mathrm{TiO}_{2}$ shell and $\mathrm{Fe}_{3} \mathrm{O}_{4}$ nanoparticles could increase the lifetime of photogenerated holes which in turn, resulted in increased photoreactivity $[3,4]$. This is attributed to the $\mathrm{SiO}_{2}$ layer which serves as an insulating layer between $\mathrm{Fe}_{3} \mathrm{O}_{4}$ nanoparticles (hole-electron trap center) and the $\mathrm{TiO}_{2}$ shell.

However, there are currently very few literature which report on the synthesis of $\mathrm{Fe}_{3} \mathrm{O}_{4} / \mathrm{SiO}_{2} / \mathrm{TiO}_{2}$ core-shell nanoparticles and their photocatalytic properties. Besides, the reported synthesis methods for $\mathrm{Fe}_{3} \mathrm{O}_{4} / \mathrm{SiO}_{2}$ nanoparticles were generally complicated and time consuming. Besides, the coating of $\mathrm{Fe}_{3} \mathrm{O}_{4}$ with $\mathrm{SiO}_{2}$ using TEOS was a very slow process which required 12 to 48 hours of mechanical stirring at room temperature [5]. Santra et al. used the microemulsion method for the preparation of $\mathrm{Fe}_{3} \mathrm{O}_{4} / \mathrm{SiO}_{2} / \mathrm{TiO}_{2}$ core-shell nanoparticles which was a lengthy process and involved the use of several types of surfactants [6]. Gad-Allah et al. and Watson et al. reported the preparation of $\mathrm{Fe}_{3} \mathrm{O}_{4} / \mathrm{SiO}_{2} / \mathrm{TiO}_{2}$ nanocomposites $[4,7]$. However, $\mathrm{Fe}_{3} \mathrm{O}_{4} / \mathrm{SiO}_{2} / \mathrm{TiO}_{2}$ coreshell nanoparticles prepared by them were in the form of patches and not discrete nanoparticles. As such, these coreshell nanoparticles exhibited in reduction on their surface area and photocatalytic properties. Song and Gao reported the use of the sol-gel process to synthesize $\mathrm{Fe}_{3} \mathrm{O}_{4} / \mathrm{SiO}_{2} / \mathrm{TiO}_{2}$ nanoparticles but the particles synthesized were very big size of about $500 \mathrm{~nm}[8]$.

Herein, we have reported a facile and efficient synthesis approach for the fabrication of $\mathrm{Fe}_{3} \mathrm{O}_{4} / \mathrm{SiO}_{2} / \mathrm{TiO}_{2}$ discrete core-shell nanoparticles by the sol-gel method with the aid 


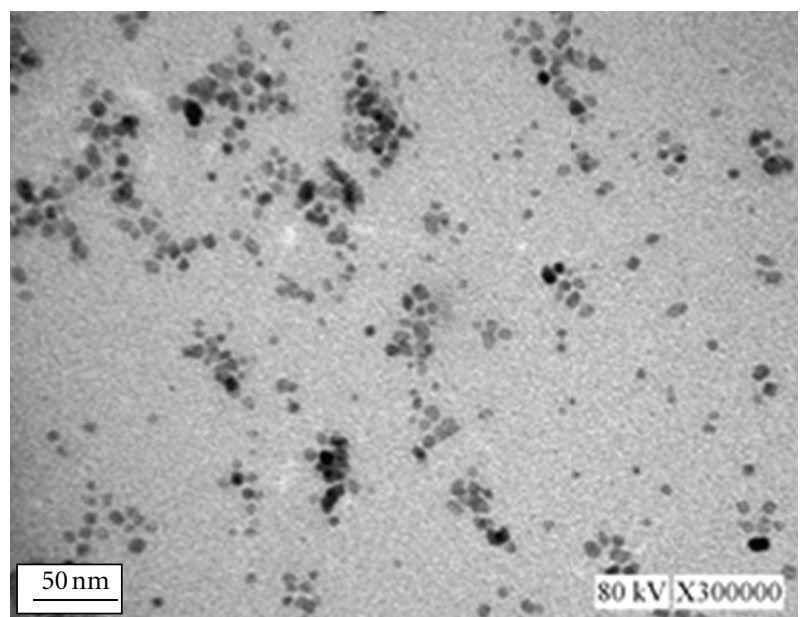

FIGURE 1: $\mathrm{Fe}_{3} \mathrm{O}_{4}$ nanoparticles were used as seeds for coating of $\mathrm{SiO}_{2}$ and $\mathrm{TiO}_{2}$ shells.

of sonication. $\mathrm{Fe}_{3} \mathrm{O}_{4}$ nanoparticles were being encapsulated inside discrete $\mathrm{SiO}_{2}$ nanospheres within 90 minutes, and a $\mathrm{TiO}_{2}$ layer was then coated directly onto each $\mathrm{SiO}_{2}$ nanosphere via the sol-gel method. The photocatalyst properties of as-synthesized $\mathrm{Fe}_{3} \mathrm{O}_{4} / \mathrm{SiO}_{2} / \mathrm{TiO}_{2}$ core-shell nanoparticles were evaluated by the photodegradation of methylene blue (MB) with or without UV light irradiation.

\section{Materials and Methods}

2.1. Materials. Iron (II) chloride tetrahydrate, $\mathrm{FeCl}_{2} \cdot 4 \mathrm{H}_{2} \mathrm{O}$ (Merck); Iron (III) chloride 6-hydrate, $\mathrm{FeCl}_{3} \cdot 6 \mathrm{H}_{2} \mathrm{O}$ (AnalaR); tetraorthosilicate, TEOS (99.3\%, J.T. Baker); absolute ethanol, EtOH (99.0\%, HmBG Chemicals); hydrochloric acid, $\mathrm{HCl}$ (37\%, HmbG Chemicals); ammonia solution, $\mathrm{NH}_{4} \mathrm{OH}(28 \%, \mathrm{R} \& \mathrm{M}$ Chemicals); titanium (IV) isopropoxide, TIPP (97\%, Aldrich); and Milli-Q water (18.2 $\left.\mathrm{M} \Omega \mathrm{cm}^{-1}\right)$ were used throughout the experiment. All chemicals were used as received without further purification.

2.2. Preparation of $\mathrm{Fe}_{3} \mathrm{O}_{4}$ Nanoparticles. $\mathrm{Fe}_{3} \mathrm{O}_{4}$ nanoparticles were prepared using a simple chemical coprecipitation method [8]. Typically, $0.15 \mathrm{moL}$ of $\mathrm{FeCl}_{2} \cdot 4 \mathrm{H}_{2} \mathrm{O}$ and $0.30 \mathrm{moL}$ of $\mathrm{FeCl}_{3} \cdot 6 \mathrm{H}_{2} \mathrm{O}$ were freshly prepared in aqueous $\mathrm{HCl}(2 \mathrm{M})$, respectively. Both $\mathrm{FeCl}_{2} \cdot 4 \mathrm{H}_{2} \mathrm{O}$ and $\mathrm{FeCl}_{3} \cdot 6 \mathrm{H}_{2} \mathrm{O}$ aqueous solution were then added rapidly to $20 \mathrm{~mL}$ of deaerated Milli-Q water under nitrogen flow at $80^{\circ} \mathrm{C}$ with the mixture being continuously stirred under nitrogen. Upon adding an aqueous $\mathrm{NH}_{4} \mathrm{OH}$ solution $(28 \%, 4 \mathrm{~mL})$, a distinctive black precipitate of $\mathrm{Fe}_{3} \mathrm{O}_{4}$ nanoparticles was formed immediately. $\mathrm{Fe}_{3} \mathrm{O}_{4}$ nanoparticles were isolated and purified by centrifugation and then washed with Milli-Q water three to four times to remove excess $\mathrm{NH}_{4} \mathrm{OH}$ solution.

2.3. Preparation of Magnetite/Silica $\left(\mathrm{Fe}_{3} \mathrm{O}_{4} / \mathrm{SiO}_{2}\right)$ Core-Shell Nanoparticles. A modified Stöber method was used to coat $\mathrm{Fe}_{3} \mathrm{O}_{4}$ nanoparticles with $\mathrm{SiO}_{2}$ shell [9]. About $30 \mathrm{mg}$ of freshly prepared $\mathrm{Fe}_{3} \mathrm{O}_{4}$ nanoparticles were dispersed in a mixture of $30 \mathrm{~mL}$ of ethanol and $6 \mathrm{~mL}$ water as seeds.
The dispersion was homogenized by sonication for about 10 minutes. $3.3 \mathrm{mmol}$ of TEOS was then added into the mixture and sonicated for another 20 minutes. Finally, $30 \mathrm{mmol}$ of aqueous ammonia was added and the mixture was sonicated for 60 minutes. $\mathrm{Fe}_{3} \mathrm{O}_{4} / \mathrm{SiO}_{2}$ core-shell nanoparticles were isolated by magnetically separation and then washed with ultrapure water.

2.4. Preparation of $\mathrm{Fe}_{3} \mathrm{O}_{4} / \mathrm{SiO}_{2} / \mathrm{TiO}_{2}$ Core-Shell Nanoparticles. A layer of $\mathrm{TiO}_{2}$ shell was coated directly onto $\mathrm{Fe}_{3} \mathrm{O}_{4} /$ $\mathrm{SiO}_{2}$ nanoparticles via the hydrolysis and condensation of TIPP in the presence of $\mathrm{Fe}_{3} \mathrm{O}_{4} / \mathrm{SiO}_{2}$ nanoparticles as seeds. $0.36 \mathrm{~mL}$ of TIPP was added into $\mathrm{Fe}_{3} \mathrm{O}_{4} / \mathrm{SiO}_{2}$ suspension and stirred continuously for 18 hours at room temperature. The resulting $\mathrm{Fe}_{3} \mathrm{O}_{4} / \mathrm{SiO}_{2} / \mathrm{TiO}_{2}$ core-shell nanoparticles were dried in an oven and finally calcined at $450^{\circ} \mathrm{C}$ for 3 hours to convert the $\mathrm{TiO}_{2}$ outer shell from amorphous phase to photocatalytically active crystalline anatase phase [10].

2.5. Photocatalytic Activity Evaluation. The photocatalytic activity of $\mathrm{Fe}_{3} \mathrm{O}_{4} / \mathrm{SiO}_{2} / \mathrm{TiO}_{2}$ core-shell nanoparticles was investigated by measuring the photodegradation rate of an aqueous solution of $\mathrm{MB}$ in the presence of $\mathrm{Fe}_{3} \mathrm{O}_{4} / \mathrm{SiO}_{2} /$ $\mathrm{TiO}_{2}$ core-shell nanoparticles and under UV irradiation. $0.02 \mathrm{mmol} \mathrm{MB}$ solution $(25 \mathrm{~mL})$ and a measured amount of $\mathrm{Fe}_{3} \mathrm{O}_{4} / \mathrm{SiO}_{2} / \mathrm{TiO}_{2}$ core-shell nanoparticles were placed inside a glass vial. A $6 \mathrm{~W}$ UV tube with a wavelength of $254 \mathrm{~nm}$ was used as the irradiation light source. During the photocatalytic reaction, the core-shell nanoparticles were being well dispersed by stirring the suspension continuously. At predetermined intervals of UV irradiation, a subsample of the suspension was collected and analyzed by UV-Vis spectrophotometer at its characteristics absorption wavelength $\left(\lambda_{\max }=642 \mathrm{~nm}\right)$ of MB.

2.6. Morphological Characterization. The morphologies of all samples were examined using a scanning electron microscopy (SEM) (JEOL Model JSM-5300LV) and a transmission electron microscopy (TEM) (JEOL JSM-6710F). The elemental composition of the core-shell nanoparticles were analysed by SEM associated energy-dispersed X-ray microanalysis (EDX) operated with the beam energy of $20 \mathrm{kV}$. The BET surface area analysis was conducted using the nitrogen absorption-desorption method at $77.30 \mathrm{~K}$ (Micromeritics ASAP 2010). The phase of the $\mathrm{Fe}_{3} \mathrm{O}_{4} / \mathrm{SiO}_{2} / \mathrm{TiO}_{2}$ core-shell nanoparticles was identified using an X-ray diffractometer (XRD) (RIGAKU, Getgerflex D/MAX-1C).

\section{Results and Discussion}

3.1. Preparation of $\mathrm{Fe}_{3} \mathrm{O}_{4} / \mathrm{SiO}_{2}$ Nanoparticles. In this study, $\mathrm{Fe}_{3} \mathrm{O}_{4}$ nanoparticles with mean diameter of approximately $10 \mathrm{~nm}$ (Figure 1) were prepared by a chemical coprecipitation method [11]. These $\mathrm{Fe}_{3} \mathrm{O}_{4}$ nanoparticles were subsequently used as seeds for coating of $\mathrm{SiO}_{2}$ shell.

$\mathrm{Fe}_{3} \mathrm{O}_{4}$ nanoparticles were being encapsulated within the $\mathrm{SiO}_{2}$ shells upon the hydrolysis and condensation of TEOS as new bonds of Fe-O-Si were formed between the interface of $\mathrm{Fe}_{3} \mathrm{O}_{4}$ and TEOS. Ultrasonication was used 


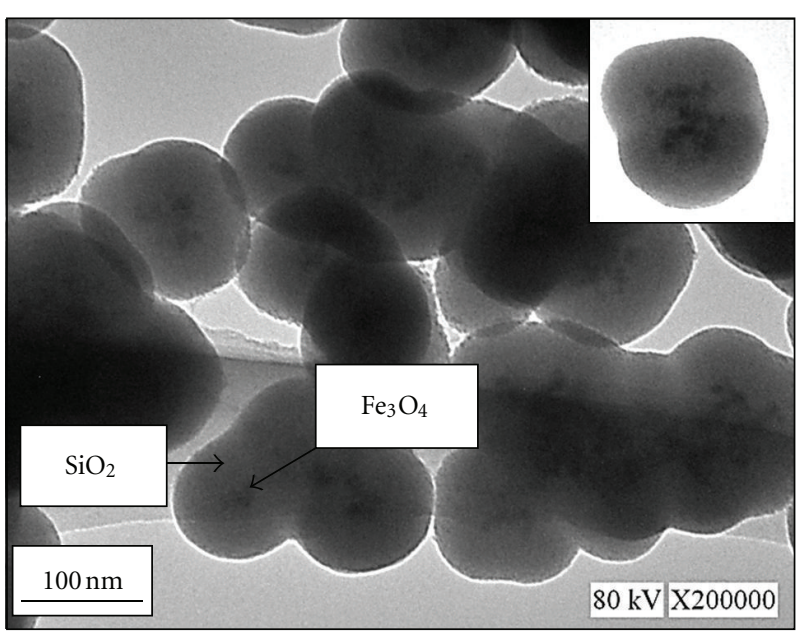

(a)

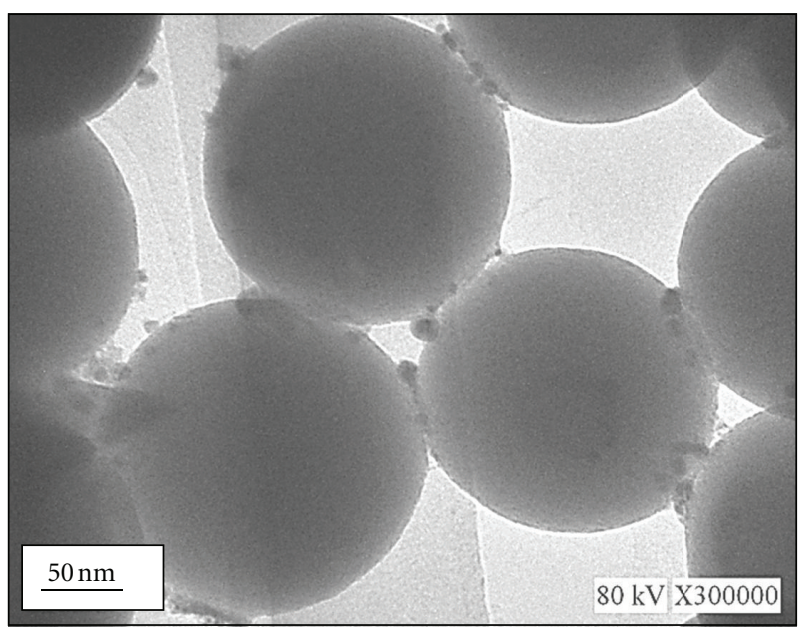

(b)

Figure 2: TEM micrographs of (a) $\mathrm{Fe}_{3} \mathrm{O}_{4} / \mathrm{SiO}_{2}$ nanoparticles prepared by sonication; inset shows an individual $\mathrm{Fe}_{3} \mathrm{O}_{4} / \mathrm{SiO}_{2}$ nanoparticles and (b) $\mathrm{Fe}_{3} \mathrm{O}_{4} / \mathrm{SiO}_{2}$ nanoparticles prepared by the stirring method.

to accelerate the hydrolysis of TEOS. This was followed by lateral polymerization, and the formation of a threedimensional network via siloxane formation ( $\mathrm{Si}-\mathrm{O}-\mathrm{Si}$ ), to produce a homogenous $\mathrm{SiO}_{2}$ coating [4]. TEM micrographs as shown in Figure 2(a) show that $\mathrm{Fe}_{3} \mathrm{O}_{4}$ nanoparticles were fully encapsulated within the $\mathrm{SiO}_{2}$ shell using the sonication method. The mean diameters of $\mathrm{Fe}_{3} \mathrm{O}_{4} / \mathrm{SiO}_{2}$ core-shell nanoparticles were observed to be approximately $120 \mathrm{~nm}$.

$\mathrm{Fe}_{3} \mathrm{O}_{4}$ nanoparticles were observed to have dispersed uniformly within the $\mathrm{SiO}_{2}$ matrix. However, $\mathrm{Fe}_{3} \mathrm{O}_{4} / \mathrm{SiO}_{2}$ core-shell nanoparticles obtained in this study were not spherical in shape after the inclusion of $\mathrm{Fe}_{3} \mathrm{O}_{4}$ nanoparticles. This could be due to the dispersing status of magnetic nanoparticles which was related to their surface charge density and in turn directed the formation of $\mathrm{Fe}_{3} \mathrm{O}_{4} / \mathrm{SiO}_{2}$ coreshell nanoparticles of various morphologies and structures [12].

Besides the sonication method, the stirring method was also being used for coating $\mathrm{Fe}_{3} \mathrm{O}_{4}$ nanoparticles with $\mathrm{SiO}_{2}$ shell. However, this approach had failed to encapsulate all the $\mathrm{Fe}_{3} \mathrm{O}_{4}$ nanoparticles within the $\mathrm{SiO}_{2}$ shells, as shown in Figure 2(b). This shows that sonication is an effective way for rapid coating of $\mathrm{Fe}_{3} \mathrm{O}_{4}$ nanoparticles core with the $\mathrm{SiO}_{2}$ shells. Besides, the high speed of coating by the sonication method had prevented the oxidation and aggregation of $\mathrm{Fe}_{3} \mathrm{O}_{4}$ nanoparticles. $\mathrm{Fe}_{3} \mathrm{O}_{4} / \mathrm{SiO}_{2}$ core-shell nanoparticles prepared in this study were more discrete and uniform in size as compared to that reported by Morel et al. who had also used the sonication method for coating $\mathrm{Fe}_{3} \mathrm{O}_{4}$ nanoparticles with $\mathrm{SiO}_{2}$ shell [5]. Deng et al. had reported on the effect of reaction parameters such as the types of alcohol, the volume ratio of alcohol to water, the amount of catalyst, and the amount of precursor on the formation of $\mathrm{Fe}_{3} \mathrm{O}_{4} / \mathrm{SiO}_{2}$ nanoparticles [13]. Although they were able to prepare nanoparticles of spherical shape, their preparation method was lengthy and required 12 hours of stirring. In this study, no surfactant was necessary during the formation of $\mathrm{Fe}_{3} \mathrm{O}_{4} / \mathrm{SiO}_{2}$ nanoparticles. Stjerndahl et al. reported that Triton-100 was used in the emulsion method for preparing $\mathrm{Fe}_{3} \mathrm{O}_{4} / \mathrm{SiO}_{2}$ core-shell nanoparticles [14]. Kobayashi et al. also reported on the need to modify the surfaces of $\mathrm{Fe}_{3} \mathrm{O}_{4}$ nanoparticles with silane coupling agent before the preparation of $\mathrm{Fe}_{3} \mathrm{O}_{4} / \mathrm{SiO}_{2}$ nanoparticles [15].

\subsection{Preparation of $\mathrm{Fe}_{3} \mathrm{O}_{4} / \mathrm{SiO}_{2} / \mathrm{TiO}_{2}$ Core-Shell Nanopar-} ticles. $\mathrm{TiO}_{2}$ was deposited on $\mathrm{SiO}_{2}$ nanoparticles by the hydrolysis of TIPP precursor. Figure 3(a) shows the TEM micrograph of $\mathrm{SiO}_{2} / \mathrm{TiO}_{2}$ nanoparticles without inclusion of $\mathrm{Fe}_{3} \mathrm{O}_{4}$ nanoparticles. All of these $\mathrm{SiO}_{2} / \mathrm{TiO}_{2}$ nanoparticles were spherical in shape with rough surfaces. The direct coating of $\mathrm{TiO}_{2}$ onto surfaces of $\mathrm{Fe}_{3} \mathrm{O}_{4} / \mathrm{SiO}_{2}$ nanoparticles resulted in the formation of core-shell type structures with $\mathrm{Fe}_{3} \mathrm{O}_{4}$ nanoparticles being the cores and $\mathrm{SiO}_{2}$ and $\mathrm{TiO}_{2}$ are the shells (Figure $3(\mathrm{~b})$ ). The EDX spectrum as shown in Figure 3(c) revealed the presence of four types of elements $(\mathrm{Si}, \mathrm{Fe}, \mathrm{O}$, and $\mathrm{Ti})$. This suggested that $\mathrm{TiO}_{2}$ was being coated onto the surfaces of $\mathrm{Fe}_{3} \mathrm{O}_{4} / \mathrm{SiO}_{2}$ nanoparticles. On the basis of the above analysis and observations from TEM images, we could conclude that a thin layer of $\mathrm{TiO}_{2}$ layer of approximately $20-30 \mathrm{~nm}$ in thickness had been coated onto the surfaces of $\mathrm{Fe}_{3} \mathrm{O}_{4} / \mathrm{SiO}_{2}$ nanoparticles (Figure 3(b)). The overall mean diameters of $\mathrm{Fe}_{2} \mathrm{O}_{3} / \mathrm{SiO}_{2} / \mathrm{TiO}_{2}$ core-shell nanoparticles were approximately $140 \mathrm{~nm}$.

Figure 4 shows the XRD pattern of $\mathrm{Fe}_{2} \mathrm{O}_{3} / \mathrm{SiO}_{2} / \mathrm{TiO}_{2}$ core-shell nanoparticles after calcination at $450^{\circ} \mathrm{C}$ in air. The broad peaks were characteristic of the $\mathrm{SiO}_{2}$ matrix [15]. The XRD patterns also demonstrated that the apparently amorphous nature of $\mathrm{TiO}_{2}$ coated on the surface of $\mathrm{Fe}_{2} \mathrm{O}_{3} / \mathrm{SiO}_{2}$ nanoparticles. In this case, the anatase phase of $\mathrm{TiO}_{2}$ could have been formed after heat treatment at $450^{\circ} \mathrm{C}$ for 3 hours $[3,8]$. The BET specific surface area of $\mathrm{Fe}_{3} \mathrm{O}_{4} / \mathrm{SiO}_{2} / \mathrm{TiO}_{2}$ core-shell nanoparticles prepared in this study was $138 \mathrm{~m}^{2} / \mathrm{g}$, and this value was substantially 


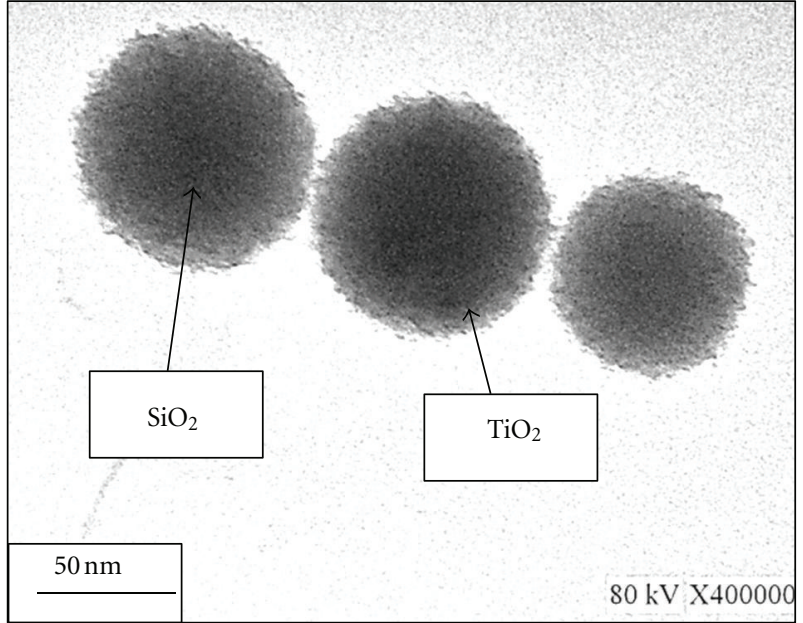

(a)

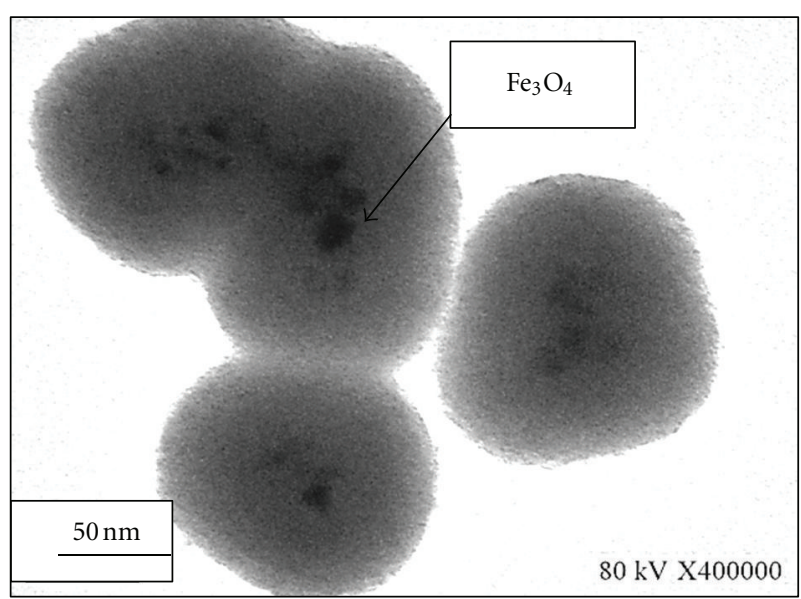

(b)

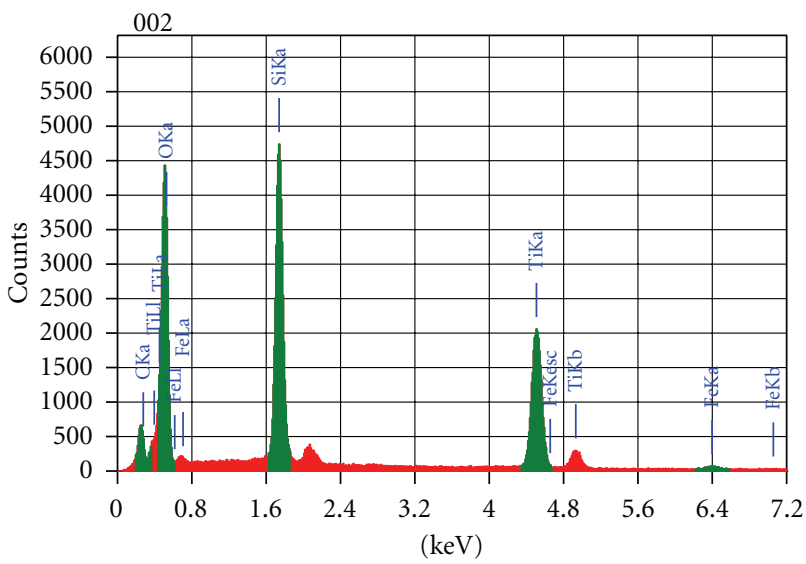

(c)

Figure 3: TEM micrograph of (a) $\mathrm{SiO}_{2} / \mathrm{TiO}_{2}$ nanoparticles, (b) $\mathrm{Fe}_{3} \mathrm{O}_{4} / \mathrm{SiO}_{2} / \mathrm{TiO}_{2}$ nanoparticles, and (c) $\mathrm{EDX}$ spectra of $\mathrm{Fe}_{3} \mathrm{O}_{4} / \mathrm{SiO}_{2} / \mathrm{TiO}{ }_{2}$ core-shell nanoparticles.

higher than that of $\mathrm{Fe}_{3} \mathrm{O}_{4} / \mathrm{SiO}_{2} / \mathrm{TiO}_{2}$ core-shell nanoparticles reported by Gad-Allah et al. at 21-54 $\mathrm{m}^{2} / \mathrm{g}$ [4]

Figure 5 presents a photograph of the $\mathrm{Fe}_{3} \mathrm{O}_{4} / \mathrm{SiO}_{2} / \mathrm{TiO}_{2}$ aqueous dispersion before and after a magnet was being attached to the outside of the sample vial. $\mathrm{Fe}_{3} \mathrm{O}_{4} / \mathrm{SiO}_{2} / \mathrm{TiO}_{2}$ core-shell nanoparticles were observed to be attracted to the magnet being attached outside of the sample vial. The result indicated that even after coating of both $\mathrm{SiO}_{2}$ and $\mathrm{TiO}_{2}$ layers unto $\mathrm{Fe}_{3} \mathrm{O}_{4}$ nanoparticles, their magnetic property had remained intact. As such, these $\mathrm{Fe}_{3} \mathrm{O}_{4} / \mathrm{SiO}_{2} / \mathrm{TiO}_{2}$ core-shell nanoparticles could be easily recovered after their application in the aqueous medium.

\subsection{Photocatalytic Properties of $\mathrm{Fe}_{3} \mathrm{O}_{4} / \mathrm{SiO}_{2} / \mathrm{TiO}_{2}$ Core-Shell} Nanoparticles. Figure 6 shows the degradation of MB dye with and without $\mathrm{Fe}_{3} \mathrm{O}_{4} / \mathrm{SiO}_{2} / \mathrm{TiO}_{2}$ core-shell nanoparticles added at various duration with and without UV irradiation. It was observed that without UV irradiation, the

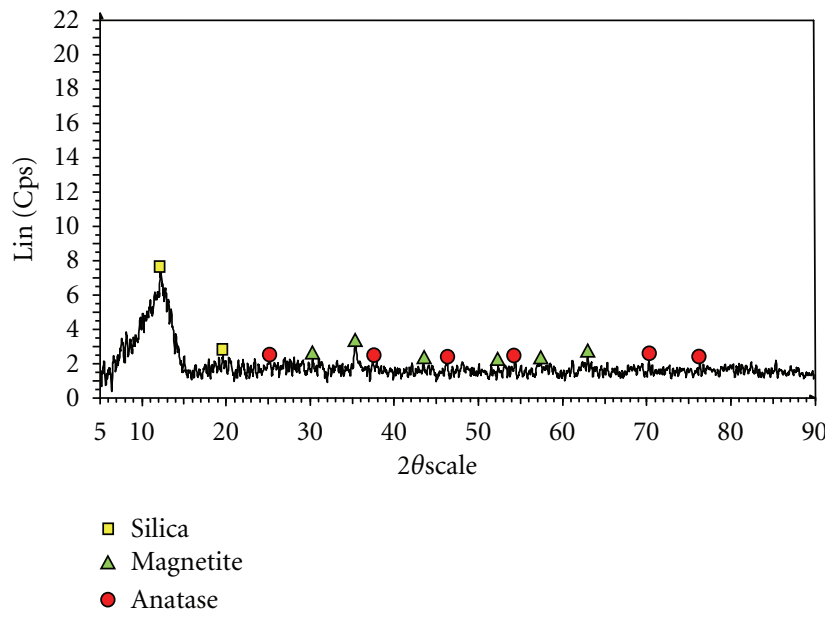

FIGURE 4: XRD pattern of $\mathrm{Fe}_{3} \mathrm{O}_{4} / \mathrm{SiO}_{2} / \mathrm{TiO}_{2}$ core-shell nanoparticles after being calcined at $450^{\circ} \mathrm{C}$ in air. 


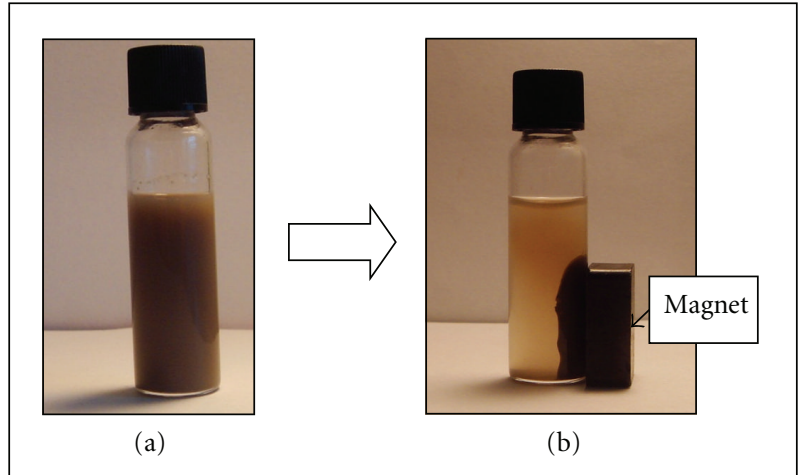

FIGURE 5: Photographs of a vial containing (a) $\mathrm{Fe}_{3} \mathrm{O}_{4} / \mathrm{SiO}_{2} / \mathrm{TiO}_{2}$ core-shell aqueous dispersion and (b) when a magnet was attached to the outside of the sample vial.

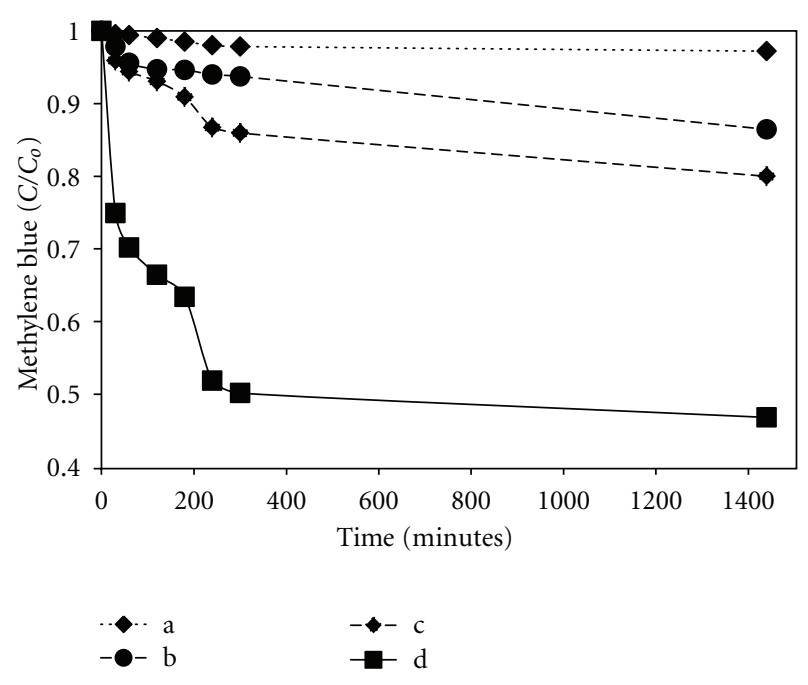

FIGURE 6: Changes in concentration of MB dye (a) alone, no UV irradiation, (b) alone, UV irradiation, (c) with $\mathrm{Fe}_{3} \mathrm{O}_{4} / \mathrm{SiO}_{2} / \mathrm{TiO}_{2}$ core-shell nanoparticles, no UV Irradiation, and (d) with $\mathrm{Fe}_{3} \mathrm{O}_{4}$ / $\mathrm{SiO}_{2} / \mathrm{TiO}_{2}$ core-shell nanoparticles, UV irradiation.

concentration of $\mathrm{MB}$ dye alone remained almost constant after 24 hours. However, its concentration decreased by about $20 \%$ with UV irradiation. The degradation of $\mathrm{MB}$ dye was substantially enhanced by the addition of $\mathrm{Fe}_{3} \mathrm{O}_{4} / \mathrm{SiO}_{2} / \mathrm{TiO}_{2}$ core-shell nanoparticles with its concentration being degraded by up to $70 \%$ with UV irradiation (Figure 6(d)). We can therefore conclude that the degradation of $\mathrm{MB}$ dye was attributed to the photocatalytic activities of the $\mathrm{TiO}_{2}$ layer on the core-shell nanoparticles.

The photocatalytic decomposition of $\mathrm{MB}$ dye catalyzed by $\mathrm{Fe}_{3} \mathrm{O}_{4} / \mathrm{SiO}_{2} / \mathrm{TiO}_{2}$ core-shell nanoparticles was further evidenced in Figure 7, which shows UV spectra of photocatalytic decomposition of $\mathrm{MB}$ dye with and without addition of $\mathrm{Fe}_{3} \mathrm{O}_{4} / \mathrm{SiO}_{2} / \mathrm{TiO}_{2}$ core-shell nanoparticles, as well as with and without UV irradiation. The intensity of absorption at around $650 \mathrm{~nm}\left(\lambda_{\max }\right)$ was observed to decrease gradually over the one-hour duration of UV irradiation in the presence

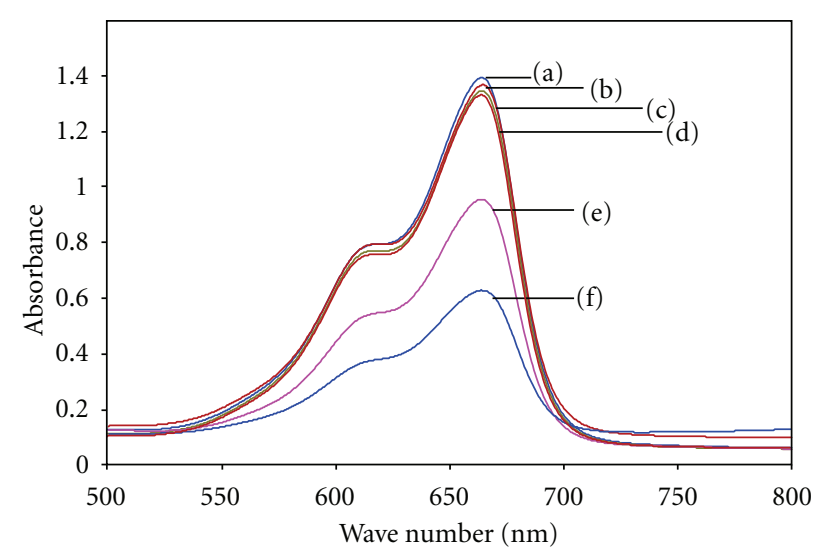

Figure 7: Absorption of MB dye solution $\left(10^{-5} \mathrm{M}, 20 \mathrm{~mL}\right)$, (a) alone, no UV irradiation, (b) alone, UV irradiation, (c) with $\mathrm{Fe}_{3} \mathrm{O}_{4} / \mathrm{SiO}_{2} / \mathrm{TiO}_{2}$ core-shell nanoparticles $(5 \mathrm{mg})$ added, no UV irradiation, (30 mg) (d) $\mathrm{Fe}_{3} \mathrm{O}_{4} / \mathrm{SiO}_{2} / \mathrm{TiO}_{2}$ core-shell nanoparticles $(30 \mathrm{mg})$ added, no UV irradiation, (e) with $\mathrm{Fe}_{3} \mathrm{O}_{4} / \mathrm{SiO}_{2} / \mathrm{TiO}_{2}$ core-shell nanoparticles ( $5 \mathrm{mg}$ ) added, UV irradiation, and (f) with $\mathrm{Fe}_{3} \mathrm{O}_{4} / \mathrm{SiO}_{2} / \mathrm{TiO}_{2}$ core-shell nanoparticles $(30 \mathrm{mg})$ added, UV irradiation.

of $\mathrm{Fe}_{3} \mathrm{O}_{4} / \mathrm{SiO}_{2} / \mathrm{TiO}_{2}$ core-shell nanoparticles. The intensity of absorption of $\mathrm{MB}$ dye had remained the same without UV irradiation.

\section{Conclusion}

In this study, a simple and facile synthesis approach was developed for the preparation of a magnetically separable photocatalyst consisting of an $\mathrm{Fe}_{3} \mathrm{O}_{4}$ core, an $\mathrm{SiO}_{2}$ intermediate layer, and a photocatalytically active $\mathrm{TiO}_{2}$ shell. This synthesis method was rapid and did not require the addition of any surfactant to direct the formation of $\mathrm{SiO}_{2}$ or $\mathrm{TiO}_{2}$ shells. The photocatalytic activity of $\mathrm{TiO}_{2}$ surface shell was not affected by the intermediate $\mathrm{SiO}_{2}$ layer and $\mathrm{Fe}_{3} \mathrm{O}_{4}$ core. The $\mathrm{Fe}_{3} \mathrm{O}_{4} / \mathrm{SiO}_{2} / \mathrm{TiO}_{2}$ core-shell nanoparticles possessed high specific surface area of $138 \mathrm{~m}^{2} / \mathrm{g}$ and exhibited a good photocatalytic activity for the photodegradation of $\mathrm{MB}$ dye in aqueous solution.

\section{Acknowledgment}

This work was supported in part by the Universiti Malaysia Sarawak under the special fundamental research Grant 01(K03)/557/2005(56).

\section{References}

[1] E. Beyers, E. Biermans, S. Ribbens et al., "Combined $\mathrm{TiO}_{2}$ / $\mathrm{SiO}_{2}$ mesoporous photocatalysts with location and phase controllable $\mathrm{TiO}_{2}$ nanoparticles," Applied Catalysis B, vol. 88, no. 3-4, pp. 515-524, 2009.

[2] A. Hanprasopwattana, S. Srinivasan, A. G. Sault, and A. K. Datye, "Titania coatings on monodisperse silica spheres (characterization using 2-propanol dehydration and TEM)," Langmuir, vol. 12, no. 13, pp. 3173-3179, 1996. 
[3] Y. Li, M. Zhang, M. Guo, and X. Wang, "Preparation and properties of a nano $\mathrm{TiO}_{2} / \mathrm{Fe}_{3} \mathrm{O}_{4}$ composite superparamagnetic photocatalyst," Rare Metals, vol. 28, no. 5, pp. 423-427, 2009.

[4] T. A. Gad-Allah, S. Kato, S. Satokawa, and T. Kojima, "Role of core diameter and silica content in photocatalytic activity of $\mathrm{TiO}_{2} / \mathrm{SiO}_{2} / \mathrm{Fe}_{3} \mathrm{O}_{4}$ composite," Solid State Sciences, vol. 9, no. 8, pp. 737-743, 2007.

[5] A. L. Morel, S. I. Nikitenko, K. Gionnet et al., "Sonochemical approach to the synthesis of $\mathrm{Fe}_{3} \mathrm{O}_{4} @ \mathrm{SiO}_{2}$ core-shell nanoparticles with tunable properties," ACS Nano, vol. 2, no. 5, pp. 847-856, 2008.

[6] S. Santra, R. Tapec, N. Theodoropoulou, J. Dobson, A. Hebard, and W. Tan, "Synthesis and characterization of silicacoated iron oxide nanoparticles in microemulsion: the effect of nonionic surfactants," Langmuir, vol. 17, no. 10, pp. 29002906, 2001.

[7] S. Watson, J. Scott, D. Beydoun, and R. Amal, "Studies on the preparation of magnetic photocatalysts," Journal of Nanoparticle Research, vol. 7, no. 6, pp. 691-705, 2005.

[8] X. Song and L. Gao, "Fabrication of bifunctional titania/silicacoated magnetic spheres and their photocatalytic activities," Journal of the American Ceramic Society, vol. 90, no. 12, pp. 4015-4019, 2007.

[9] H. S. Yang, S. Y. Choi, S. H. Hyun, H. H. Park, and J. K. Hong, "Ambient-dried low dielectric $\mathrm{SiO}_{2}$ aerogel thin film," Journal of Non-Crystalline Solids, vol. 221, no. 2-3, pp. 151-156, 1997.

[10] S. F. Chin, S. C. Pang, and F. E. I. Dom, "Sol-gel synthesis of silver/titanium dioxide $\left(\mathrm{Ag} / \mathrm{TiO}_{2}\right)$ core-shell nanowires for photocatalytic applications," Materials Letters, vol. 65, no. 1718, pp. 2673-2675, 2011.

[11] S. C. Pang, W. H. Khoh, and S. F. Chin, "Nanoparticulate magnetite thin films as electrode materials for the fabrication of electrochemical capacitors," Journal of Materials Science, vol. 45, no. 20, pp. 5598-5604, 2010.

[12] K. S. Rao, K. El-Hami, T. Kodaki, K. Matsushige, and K. Makino, "A novel method for synthesis of silica nanoparticles," Journal of Colloid and Interface Science, vol. 289, no. 1, pp. 125131, 2005.

[13] Y. H. Deng, C. C. Wang, J. H. Hu, W. L. Yang, and S. K. Fu, "Investigation of formation of silica-coated magnetite nanoparticles via sol-gel approach," Colloids and Surfaces A, vol. 262, no. 1-3, pp. 87-93, 2005.

[14] M. Stjerndahl, M. Andersson, H. E. Hall, D. M. Pajerowski, M. W. Meisel, and R. S. Duran, "Superparamagnetic $\mathrm{Fe}_{3} \mathrm{O}_{4} / \mathrm{SiO}_{2}$ nanocomposites: enabling the tuning of both the iron oxide load and the size of the nanoparticles," Langmuir, vol. 24, no. 7, pp. 3532-3536, 2008.

[15] Y. Kobayashi, S. Saeki, M. Yoshida, D. Nagao, and M. Konno, "Synthesis of spherical submicron-sized magnetite/silica nanocomposite particles," Journal of Sol-Gel Science and Technology, vol. 45, no. 1, pp. 35-41, 2008. 

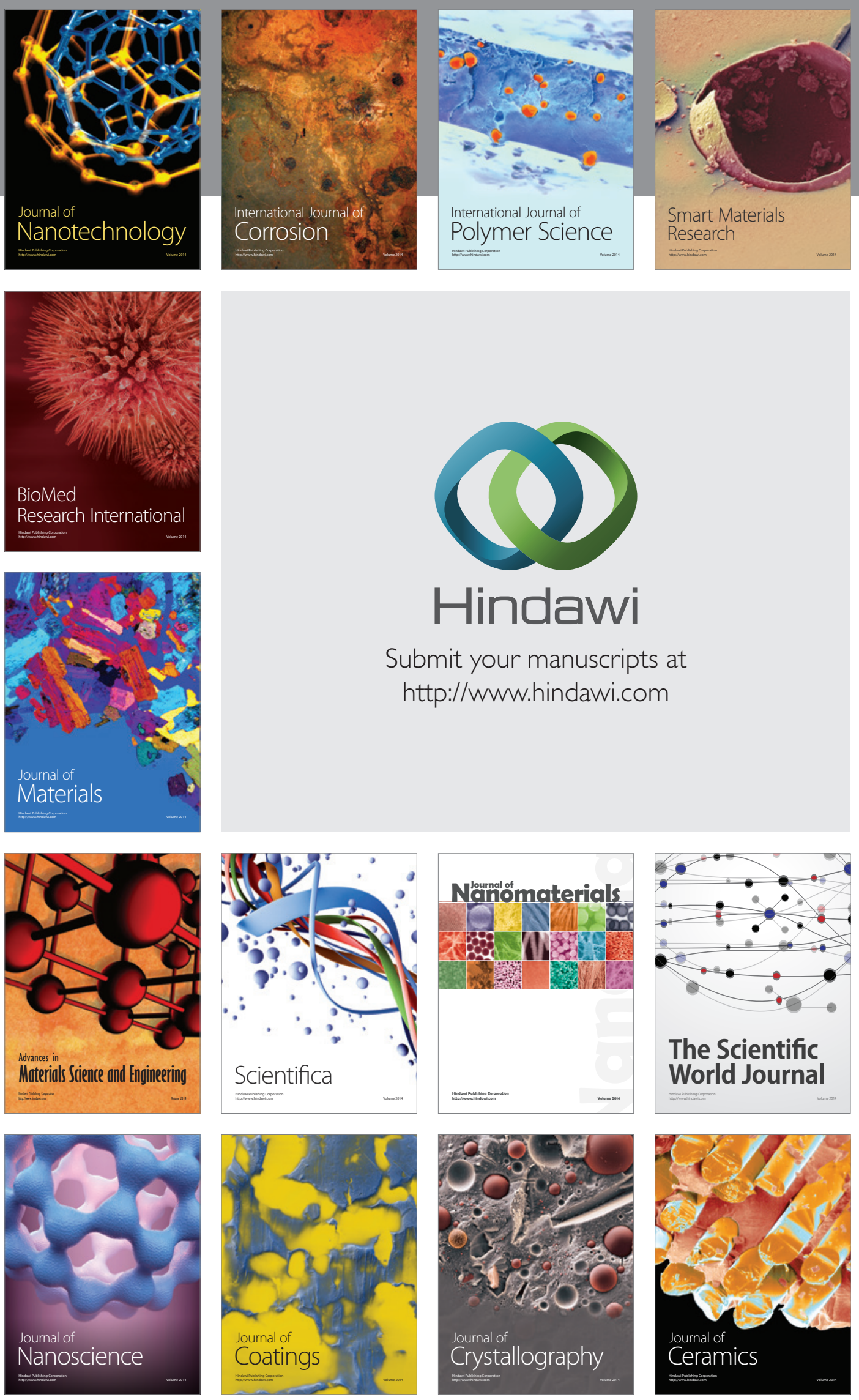

The Scientific World Journal

Submit your manuscripts at

http://www.hindawi.com

\section{World Journal}

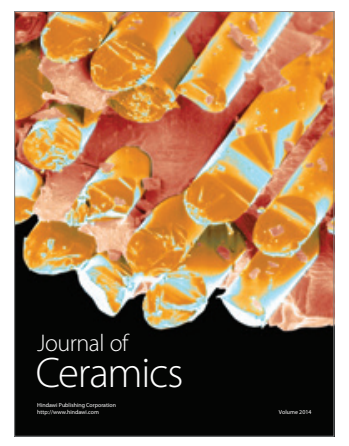

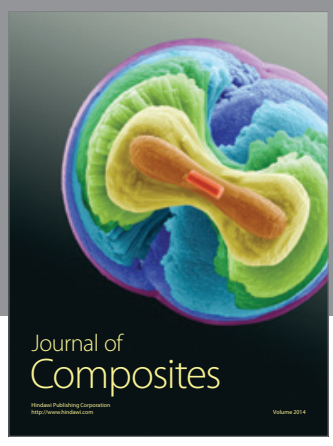
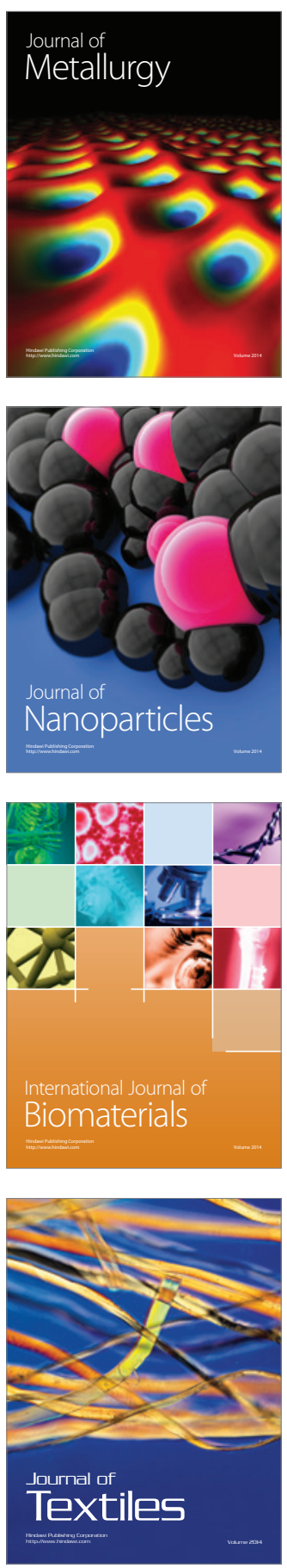